\title{
TOWARDS THE NEXT ICOTS10 IN KYOTO
}

\author{
Michiko Watanabe $^{1}$ and Kazunori Yamaguchi ${ }^{2}$ \\ ${ }^{1}$ Keio University, Japan \\ ${ }^{2}$ Rikkyo University, Japan \\ watanabe_michiko@nifty.com
}

The International Conference On Teaching Statistics [ICOTS] is held every four years. Its main purpose is to give statistics educators and professionals around the world the opportunity to exchange information, ideas and experiences, by presenting recent innovation and research in statistics education. ICOTS also allows people to expand their range of collaborators.

We are at a critical time in statistics education where the world of data is changing rapidly. We need to be looking ahead to how as a field we will evolve and engage with the future. At the same time, we are celebrating our tenth ICOTS and this marks a time for us to look back on the past 40 years since 1978, when the ISI's Education Committee Task Force was established to plan for the first ICOTS. This is indeed an exciting time.

Statistics education has matured as a field. Data have become part of everyday life, vital for professions and part of our very fabric as a society. Data are used everywhere to document, evaluate, plan and persuade. The very nature of what we call "data" is not what it was 10 years ago - or even last year. Data science is emerging as a new field. Yet, it is not clear if statistics and data science are moving together or apart. Both areas focus on variability, uncertainty and context, but often approach the analysis and collection of data quite differently. In terms of education, what can the fields learn from each other? Where do we see ourselves going? 